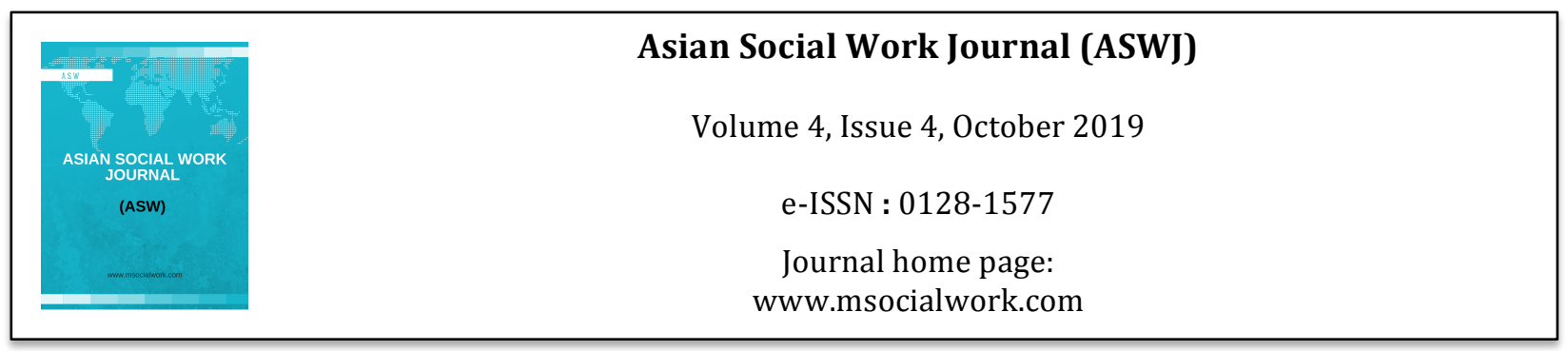

\title{
Reflexivity: Doing Research with Women in a Mental health Care Facility
}

\author{
Phooi Ling Yong', Faizah Mas'ud ${ }^{2}$, Ling How Kee ${ }^{2}$ \\ ${ }^{1}$ Faculty of Social Sciences and Humanities, Universiti Malaysia Sarawak (UNIMAS) \\ ${ }^{2}$ Centre of Disability Studies, Faculty of Social Sciences and Humanities, Universiti Malaysia Sarawak (UNIMAS) \\ Corrrespondence: Phooi Ling Yong (phooi_ling@hotmail.com)
}

\begin{abstract}
Reflexivity has been recognised as a crucial strategy in the knowledge generating process and applied in qualitative research to legitimate, validate and question research practices and representation, as well as evaluating the quality of qualitative research. Reflexivity in the social work literature have impacted in research and practice. However, the effect of researcher's perspectives on the data collection and interpretation process by using reflexivity has not been examined in the mental health research in Malaysia. Thus, this paper aims to explore the role of methodological reflexivity in a qualitative research with Chinese women with mental health problems in a residential care setting in Malaysia. The researcher's and participants' interaction and experiences, as well as emotional context during interviews that affect the data interpretation and data collection process are discussed. Greater understanding on their experiences in the care centre has been generated by focusing on these women as an "abled-body" rather than people with disabilities. Recognition of the researcher's feelings and experiences have enriched the research method and analysis, as well as informing the practice for social workers, health practitioners, and students who work with women with mental health problems.
\end{abstract}

Key words: women, mental health, care facility, social work

\section{Introduction}

Reflexivity has been recognised as a crucial strategy in the knowledge generating process and for evaluating the quality of qualitative research (Berger, 2015). It is also used in qualitative research to legitimate, validate and question research practices and representations (Pillow, 2003). Palaganas, Sanchez, Molintas, and Caricativo (2017) point out that qualitative researchers were affected throughout the research process, and thus they used reflexivity to recognize the changes brought in themselves that have affected and caused by the research process from the influence of their characteristics and experiences. According to Mays and Pope (2000), reflexivity means

\section{"sensitivity to the ways in which the researcher and the research process have shaped the collected data, including the role of prior assumptions and experience, which can influence even the most avowedly inductive inquiries" (p.51)}

Probst and Berencon (2014) defined reflexivity as the researcher's awareness on the influence of what is being studied and how the research process affects the researcher simultaneously. Thus, reflexivity is a tool which uses the "self" at any stage and makes the researchers' values and beliefs apparent that impacted the research process and its outcomes (Etherington, 2007). Reflexivity represents a process that unfolds throughout the entire research process instead of just occurs at one point in time 
(Guillemin \& Gillam, 2004). It can be discussed in the method section of a writing or a self-disclosure statement where the researchers acknowledge their own biases and report their potential influence on the findings to be evidence in the research article (Lietz \& Zayas, 2010).

Longhofer and Floersch (2012) divided reflexivity into seven modalities such as personal reflexivity addresses how the steps in the research process are shaped by a researcher's values, assumptions, experiences, training, aims, positioning, and identities; methodological reflexivity involves the researcher to question how the data collected is limited by the research design and method; and analytic reflexivity requests how to analyse the data with each theory and analytic choice that interpreting some understandings visible and others invisible. The purpose of reflexivity is to enhance the research quality through its ability to extend the understanding of researchers' positions and interest which might affect all the research process stages (Primeau, 2003) and recognise the impact of self on the influence this understanding into how the professional decisions are made (Morley, 2015).

\section{Reflexivity in Mental Health Research}

The concept of "reflexivity" has been discussed in social work literature since 1990s (Fook, 1999; D'Cruz, Gillingham, \& Melendez, 2007; Morley, 2015). Reflexivity within the social work literature (D’Cruz, Gillingham, \& Melendez, 2007; Lietz \& Zayas, 2010; Probst \& Berenson, 2014) carried out important implications for informing research and practice, and as a requirement to evaluate qualitative social work research (Morley, 2015). A past study conducted by Barusch, Gringeri, and George (2011) described the strategies used by social work researchers to enhance the rigour in their research work, the finding showed that one of the strategies used was reflexivity or use of self (14\%), while the most popular strategies used was sampling rationale $(67 \%)$.

Moreover, past qualitative studies have been conducted in exploring the life experiences and perspectives of the people with mental health problems (Buizza et al., 2007; Crabtree, 2004; Dinos et al., 2004; Gilburt, Rose, \& Slade, 2008; Granerud \& Severinsson, 2003; Hanafiah \& Bortel, 2015; Johnson et al., 2004; Longo \& Scior, 2004; Low \& Lee, 2015; Manuel, Hinterland, Conover, \& Herman, 2011; Owen, Repper, Perkins, \& Robinson, 1998). Within these literatures, the role of reflexivity is relatively uncommon. However, one of the past studies conducted in London by Gilburt, Rose, \& Slade (2008) to explore the admission experiences of people with mental health problems has highlighted the researchers' personal reflexivity by using memos for personal reflection and theoretical insights in data collection and analysis as an analytic tool and as a means of reflection to record their own beliefs and experiences during the coding process.

Since limited studies conducted in Malaysia are designed to examine how a Chinese researcher researching about Chinese women in a mental health care setting, thus this article aims to employ the role of methodological reflexivity as an understanding tool in conducting research with women with mental health problems by examining the researcher and participants' context and experiences before and during interview, as well as exploring the researcher's personal experiences and emotional responses in conducting research with vulnerable group participants in a care centre in Malaysia. It is hope that these insights can inform the understanding and practice as a researcher, social worker, and student who work with people with mental health problems, and recognize the researcher's feelings, experiences, and perspectives imbedded in the research findings and analysis.

\section{Data Collection Method}

To explain and illustrate the reflexive process in interviewing women with mental health problems, as a researcher, I drew upon my personal experiences of being involved in the research project for my postgraduate degree which aims to explore the experiences of women with mental health problems in a care centre. Qualitative research design, in the form of face-to-face in-depth interviews, was employed in the study. The location and participants were chosen using purposive sampling technique. Thematic analysis has guided the study for identifying themes that emerged from the data collected (Braun \& 
Clarke, 2006). The study was carried out with care and followed the research ethical guideline with vulnerable participants (Padgett, 2017).

In considering practical and methodological aspects of interviewing women with mental health problems, I highlighted upon how the interactions influenced me as a researcher, a social work student and a Chinese woman in Malaysia. Furthermore, my insider status and experiences are important because some biases and assumptions stem for it and have been argued by previous researchers about the effect of the research question, decisions about research procedures, and the data collection and analysis process as stated by Lietz and Zayas (2010). As a qualitative researcher, one should remain aware of the subjective responses that will influence the entire research process on both data collection and analysis to attend openly and actively to the participants' views. Therefore, to demonstrate reflexive process, a researcher would present data on what was going on across the entire research especially the process of analysing the meaning making of self and what a researcher understood from the literature and information gathered from the participants in the study.

The role of "self" influenced the decision made in the research process (Probst \& Berenson, 2014). For example, my personal experiences influenced my choice in choosing the individual interview rather than focus group as suggested by my supervisor, as the data collection method in my study. I chose this method based on my experience as a social work intern student at the centre where I found the participants withdrew from the communication when other residents interrupted the conversation because they shared some very personal experiences (Fossey, Harvey, McDermott, \& Davidson, 2002; Peters, 2010). Based on my observations, the participants stopped sharing their stories when other residents tried to approach the interview place to avoid others to know and discuss about their stories among themselves. Therefore, this method is chosen to ensure the research ethics particularly confidentiality throughout the research process and in managing the participant's information.

Moreover, semi-structured interview was employed because it allowed the discussion to be diverged from the interview guide to ask more interesting questions (Gill, Stewart, Treasure, \& Chadwick, 2008; Peters, 2010; Stuckey, 2013). For example, the second participant talked about the onset of her mental health problem was influenced by the "Feng Shui" "of the house as in the conversation.

R: Do you know how you get "sick" ?

P2: I know that because I...I was stress in study. Then, or maybe I... after I left Wah Keong Park then [caused me] have mental health problem. Or maybe the Feng Shui of the house affect me.

R: Do you believe in Feng Shui?

P2: That means the Feng Shui of the house is not good. After we invite the Feng Shui master to look the house, we moved to Bercham.

Being an insider, a researcher who is a member of the community being studied (Naaeke, Kurylo, Grabowski, Linton, \& Radford, 2011), the participants and I shared a similar cultural background which I can identify that cultural belief systems influenced the mental health concept (Chong, Mohamad, \& Er, 2013). Due to this, it has helped me to develop an idea on asking question related to the onset of mental health problems influenced by the participants' religion or cultural beliefs system in the following interviews which was not included in the interview guide has then helped to generate or enhance the emergent themes. Thus, face-to-face in-depth interview was chosen as the most appropriate data collection method for the study to explore the participants' experiences on topics of interest (Fossey et al., 2002; Gill et al., 2008; Peters, 2010) through a developed trusting relationship (Peters, 2010).

\footnotetext{
${ }^{1}$ Feng Shui is a traditional cultural practice based on the dynamics of qi energy in the human and natural environment of the world that affected the development of landscapes. Feng is the Chinese term for wind, and Shui is the term for water (Mills, 1999).

${ }^{2}$ The term "sick" is being used because the women are more likely to use this word instead of suffering from mental illness or mental disorder when I talked to them at the centre before.
} 
In addition, adopt an emic role, I can be myself as a Chinese female researcher since the participants and I shared the same language and cultural background. Most of the participants chose to speak Mandarin in the interview rather than English because it is the mother tongue of both the researcher and the participants can easily express their own context and term. For example, the Chinese term " $\square$ 神” or consult the Chinese tangki in English, is understood by the participants and me who affiliated Buddhism as seeking help from the traditional healers.

\section{R: Do you go to 问神 [consult the Chinese tangki in English]? \\ P9: Last time my family member always brings me to 问神 or consult the tangki. \\ [They] go everywhere to consult the tangki.}

We shared the same cultural practice and believed that the pantheon of powerful spirits that known as "Shen" in Chinese can become the mediums through their trances and deal with the devils and deities to bring change in the suffering person (Haque, 2008, 2010). As a researcher with Chinese background, I can identify with the participants' help-seeking behaviour and the perception of health either physical or mental that guided by our culture and spiritual belief.

Furthermore, I must be sensitive against assuming that we share the same language and meanings, and thus have the same understanding on their situations (Finlay, 2002) to not miss different views. At first, this has confused me as a researcher when I started interviewing the women with an assumption (based on my mental health knowledge and internship experiences) that as women we have same understanding on the same question. It then surprised me as a researcher that some participants have different views in comprehending questions illuminated their unfamiliarity as being grouped as women with mental health problems. I also did not expect that some participants unable to understand the questions and require further explanation even though pilot study was conducted before the study.

\section{Results And Discussion}

\section{Understanding the Stories}

In addition to ethical issues, the validity and reliability issues are often debated in qualitative research. Unlike quantitative research, qualitative research seeks to understand the individual construction from the participants' perspectives (Peters, 2010) by employing data collection methods such as in-depth interview, participant observation, and reviews (Polkinghorne, 1995). Since qualitative research allows readers to draw conclusions from findings, critique is thus a part of the research tradition to increase the quality of the studies (Lietz \& Zayas, 2010). Although the issues of evaluating qualitative research are often debated, the process to determine the quality of qualitative research is different based on the purposes and methods (Lietz \& Zayas, 2010). Lincoln and Guba (1985) have suggested four concepts in evaluating the qualitative research such as credibility, transferability, auditability, and conformability to achieve "trustworthiness" of the data collected.

Instead of discussing these concepts, the purpose of this article is to share with other researchers or practitioners some insights on the methodological issues when doing research with people with mental health problems. Interviewing people with mental health problems raised methodological considerations for the research (Peters, 2010). Given the participants deeply affecting content, I acknowledge the impact on how researcher interpreted and analysed the collected data guided by feminist perspectives that focus on the women's self-actualization, elimination of oppression, and advancement of all people's human dignity (Gary, Sigsby, \& Campbell, 1998). For example, I have presented this study in a colloquium organised by the faculty, the question of validity and reliability has been questioned by other researchers when they knew that the participants involved were vulnerable group such as the people with mental health problems. This was surprising to me as the perspectives of the people with mental health problems were being doubted by other researchers in

\footnotetext{
${ }^{3}$ The Chinese tangki (locally referred to as medium in English) refer to those who invoke the supernatural power in healing (Ling, 2007).
} 
providing "trustworthiness" data collected from participants who are perceived unable to participate effectively.

I understood and believed that this doubt aroused from the public due to the misconception on people with mental health problems on their ability to "think" and communicate (Malaysian Psychiatric Association, 2006). As a researcher, I believed that people with mental health problems would recover and live their life as other members of the public after going through rehabilitation process. Hence, I emphasized that the participants involved effectively and able to communicate and understand the purpose of the study. In addition, purposive sampling was used in the study in choosing the participants and those who are "apt" have participated willingly in the study. Since the study was guided by feminist perspectives, it is hoped that no discrimination or stigmatization on women with mental health problems. As such, their experiences need to be emphasized rather than viewing them as people with mental health problems who are incompetent to provide relevant data.

Moreover, feminisms provide opportunities for people to examine and experience living through a women-centre perspective (Gary, Sigsby, \& Campbell, 1998). I have been moved by the participants' narratives and often felt motivated to highlight their experiences in the care centre in the study. For example, the participants described that "I feel [that] there is no feeling. I thought that it is never mind telling others to having mental stress. Sometimes it might help others when saying it out." (P8) and "No. They didn't look down on me. My mother loves me. Just that I was sick and what to do." (P7). The research findings also emphasized the participants' experiences such as the women position in the family, decision making process, and separation experiences with family members have impacted me as a female in the Chinese community, a researcher and a student. Throughout the interview process, the rapport was enhanced, and the researcher's feeling was deeper when interacting with the participants and identifying them as a woman.

Although the validity and reliability of qualitative study always been debated, there are various ways to improve validity by requiring the researcher's and reader's judgment (Mays \& Pope, 2000). To achieve the "trustworthiness" when doing research with people with mental health problems, reflexivity has thus been chosen as an appropriate strategy in any qualitative research regardless of approach (Lietz \& Zayas, 2010). Moreover, to identify a study to be trustworthy, it is for the reader to determine whether the strategies used align with the research purpose, epistemology, the research design, and the ability to manage the research reactivity and bias (Lietz \& Zayas, 2010) instead of just questioning on the participants' ability in providing "trustworthy" data. Therefore, I wished that the participants' genuine experiences and voices can be presented to the outsiders who have no opportunity to approach and interact with these group of people and hoped that it would help to dissimulate the misconception and myths on people with mental health problems.

\section{Self and the Women}

Entering this care centre twice follows the visitation procedures allows me access to this group of women two times. The first entering to the centre as an intern student provided me an opportunity to engage and build rapport with the residents. Unlike the experiences before as an intern student at the centre, as a researcher, I must change my perspectives to locate the centre as a research environment with an advantage of familiarising with the residents and the system in place. For example, before entering to the field, permission letter was prepared and emailed to the management team to seek approval to enter the field. Although it needs time waiting for their reply, I understood that seeking permission accessing to research site and participants is a challenge in the research process to protect the vulnerable group, the women with mental health problems, or their families, and professionals from exploitation and free from coercion (McFadyen \& Rankin, 2016). While waiting for the approval letter, I also went to the centre to meet the centre's supervisor and explained the research purpose to them to gain their support and cooperation (McFadyen \& Rankin, 2016).

After gaining access to the centre, the centre staffs provided me the latest residents' information, but I was still depending on the willingness of and rapport built with the women for their participation in this research. Although rapport with the participants has been established previously, I found that there is 
pressure between the research space and participant's autonomy (Berger, 2015). The power differences between researcher and participants were more obvious when vulnerable group is involved in the interview (Berger, 2015) as the participants knew the role and purpose of the interviewer. My attempt is to ensure the participants to feel comfortable just like how they interact with me during my internship. Due to the role of the interviewer as a researcher, the participants answered the questions cooperatively and openly although I have explained to them that they could refuse to answer any question which they might feel affected in any way (Alston \& Bowles, 2003). For example, the questions asked in the interview sometimes caused the atmosphere to become condense, but the participants still answer the question.

R: How do you feel when your family members do not come to the centre to visit you? P2: (Paused) anything to sad for? (Paused again) They will come if they want to see me and care of me. After they see me, anything to be sad?

I realised that the atmosphere become awkward when the participant heard the question, but she tried to be calm and answered the question. Although I felt it is not right to do that, but none of them took the option and willing to share their stories. I was very impressed by their willingness to trust me sharing their personal stories in the interview. I understood that the appropriate data collection method which cause less discomfort and anxiety among the participants, the rapport building, and the informed consent have influenced their willingness in participation and thus helped to generate interesting data.

\section{Emotional Issues}

I anticipated the potential impact of interview questions on the participants' experiences on their past histories and stigmatization that would precipitate emotional reaction (Galea et al., 2005) since "do no harm" is the ethical concerns for research (Gibbs et al., 2018). Nonetheless, the participants appreciated the opportunity to share their knowledge on their experiences and stories. For example, a woman was initially excited when sharing her experiences, but later the atmosphere changed when the questions asked about her relationship with family members like in the conversation.

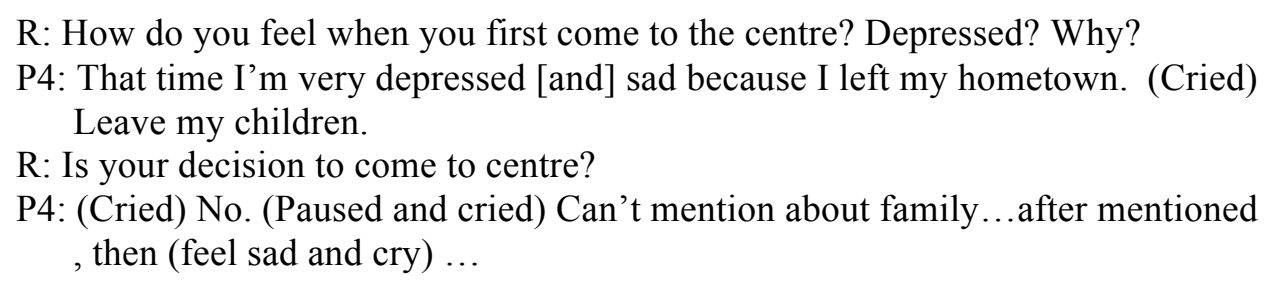

I tried to console her, at the meantime I was influenced by her and have a feeling of wanted to cry after knowing that she has separated with her children since they were young and how she tried to keep in contact with her children. Another woman was first enthusiastic in answering the question but requested to stop sharing her past stories before becoming "sick".

R: How was your first time in a relationship? Do you keep in contact with him?

P6: [My] First time [in a relationship] is [with] my colleague. Because he loves me so I keep in contact with him... Then I transferred and worked at Kelantan. After that I heard he want to marry, so I was very suffering. He is cheating my love... I get to know from others. This is the past [so I] don't want to talk more. I don't want to think back. The past is the past. It's enough to talk about it. Then, I'm okay.

I felt that the woman was influenced by her emotion when sharing her past experiences on her relationship with the colleague has interrupted the interview session. Since the participants have right to withdrew from the interview at any time if they felt offended or affected in any way, I was not surprised that they requested to stop the interview. However, the participants were willing to continue the interview once they felt comfortable and after consent was informed again. 
As a researcher, I must be transparent to the participants, but my feelings and emotion was still influenced by them. Berger (2015) mentioned that being self-reflexive thus helped researchers to identify the emphasized questions and content, and become aware of own reactions to interviews, thoughts, emotions, and triggers. Moreover, after recognising the potential impact on the participants, I tried to adopt a respectful and non-judgemental research ethics by focusing on their experiences as women rather than women with mental health problems. I wondered why the participants participated willingly and exposed their lives for further analysis because the study gave them an opportunity to focus briefly on their current circumstances, to be heard as a woman, and being respected. In generating and reviewing data, I also focused on their perception as being a woman with mental health problem to enhance the research findings. Therefore, I was often humbled and grateful in listening to the participants' stories and experiences, as well as appreciate their contribution to the study.

\title{
Unpredictable Situation
}

Undoubtedly, I realized that the participants' past histories and relationships were difficult, sad and sometimes distressing. I also witnessed the overwhelming constrains on these women in a care centre and in the society. Responding both as an empathic and a female researcher, their stories always saddened me. Their stories continue to echo that I thought I was empathetic, but my empathy and feeling is different and deeper after I read their stories again and again. For example, the participants echoed that they wanted to go home one day after spending most of their life time in the centre, separated from family member, and going through all the treatment.

\author{
P1: I definitely want to go home one day! \\ P5: I don't want to stay at centre. I can't adapt at the centre. [Even though I \\ have] stayed five, six, till ten years, I also can't adapt [at here]. [I'm] \\ still not happy. \\ P11: If I have choice, I want to go home to stay. [I] don't want to stay here.
}

As a researcher and a female student, their stories and experiences always disheartened me. After listened to their stories, I think my difficulty and feeling is insignificant. Although I did not specifically seek negative experiences, sad and distress were frequently reported.

In addition, the participants and I shared similar cultural and belief background, but there have always some differences in religion affiliation. For example, some Buddhist participants have changed their religion affiliation to Christianity which they found helpful for their mental health problems and able to act as a life guidance. It is expected that Malaysian Chinese affiliated not only one religion, they can be either a Buddhist or a Christian (Malaysia Federal Constitution, 2010). Due to the different religion affiliation, I have conducted the interview with care to avoid any sensitivity question related to religion so that the participants will not feel resisted. However, it is unexpected that I sometimes felt uncomfortable when the participants tried to promote their religion and said something bad about what I chose to belief religiously during the interview. As told by the participant on the reason of changing of religion in the conversation.

P5: After believed in God, [I] felt relief, [my] mood [become] cheerful, and there is peace in heart. I feel that Christian is the love religion. Love is priority because only [with] love, [we] will love [by] God, and [God] love people.

P6: I was hurt because of 百忍成金 [toleration is precious in English]. So, Jesus saves me. Jesus said that He is the saviour, save you from the pain. So, I like Jesus. The words from Jesus is also good, [it] won't condemn people.

Sometimes, a conflict arouses related to different views on religion affiliation that might difficult to be comprehended as a researcher and a Chinese woman (Fouka \& Mantzorou, 2011; Reid, Brown, Smith, Cope, \& Jamieson, 2018). Therefore, as an empathetic researcher, I must be understanding and listened objectively to the participants' voices and focusing on their experiences. 
Moreover, as an insider and a Chinese female, the participants and I realize that women's position confined in multifaceted layer of cultural, belief system and traditional practice (Noor, 1999) in the society and in the Chinese community. For example, the participants felt that they are placed at the second-class position in the society and family and thus could not exceed man as stated in the Bible and based on the Chinese traditional practice especially in decision making as in the conversation.

R: How do you perceived women position in society?

P6: We [women], according to the Bible, we are the boy that side (rib). [The] first girl is made from the [boy's] rib bone. Because the God created you guys (women) from the Adam's rib. So, we can't exceed the boy.

R: May I know who made the decision on centre's admission?

P5: [Admission to centre] is my father's decision. [It's] Not my decision. I don't like here. I have told about that. But he still let me to stay here. I have no idea. It's not my choice to stay here.

From the data collected, as a researcher, I understood that the participants inability of participation in decision making on their admission to and discharge from the care centre related to their position in family, belief system and cultural practice.

As a social work research student, I found it is very difficult for me when listened to the participants' distress and feeling when at that moment I have no power within the current system to help them although I acquired the social work knowledge, values and skills. For example, I could not be the mediator, a social work role who help to resolve conflicts between client systems (Ambrosino, Heffernan, Shuttlesworth, \& Ambrosino, 2012), and intervene in the relationship between the participants and their family, other residents, and centre's staffs because I know my role as a researcher and a student. During these occasions, I would remind myself not to give any promises to the participants to avoid disappointment on them which can be illustrated in the helplessness and dilemmas as a researcher in the mental health care setting (Alston \& Bowles, 2003). In order to avoid distraction from the study, as a researcher, I tried to be calm and emphasized again the purpose of the study to ensure objectivity in description and analysis.

Moreover, in the work of Barusch, Gringeri, and George (2011) found that researchers rarely provide their information on their feelings in the published social work articles because they feared that it is unprofessional or invasive to disclose their personal feelings and personal disclosure would then be inconsistent with editorial demand. However, as a qualitative researcher, objectivity and nonjudgemental are impossible when listening to the participants' narratives because focussing on experiences inevitably uncovered emotional issues (Finlay, 1998) that will influence a researcher and the participants throughout the research process. Inevitably my emotion and behaviour were affected by the participants and thus influenced the findings (Campbell, Taylor, \& McGlade, 2017). Hence, through reflexivity, the researcher's positioning such as gender, personal experiences, emotions, beliefs, and biases to participants (Berger, 2015) can enhance the data interpretation process (Lietz, Langer, \& Furman, 2006) and ensure the "trustworthiness" of the research (Lietz \& Zayas, 2010). It also helped the participants' voices to be heard and increased the probability of the work to meet the standards of quality (Lietz, Langer, \& Furman, 2006) by offering reliable and applicable social work qualitative research (Barush, Gringeri, \& George, 2011).

\section{Conclusion}

This article underlined the value of adopting reflexive process in identifying the researcher's individual experiences and how it can produce a richer understanding on women's experiences in a mental health care centre. This article focused on the aspect of understanding reflexivity in interviewing women, that is, how researcher's position in relation to the vulnerable group and issues under the study that influence the research process and analysis standpoint. It also discussed and illustrated that the researcher's experiences are a part of the study since "no research is free of the biases, assumptions, and personality of the researcher and cannot separate self from those activities in which intimately 
involved" as points out by Sword (1999). Thus, reflexivity was chosen as the strategy to improve the "trustworthiness" of the study has allowed me to express my experiences, biases and feelings throughout the research process, as well as motivated me to contribute this article by offering a rare transparency in examining the emotional impact on the study, personal self, and professional.

Recognizing the reflexivity process was adopted late in this research, I recommended the future social work researcher who is planning to conduct a qualitative research should write memo or field notes throughout the entire research process. This is because reflexivity is a continuous reflection process by researchers on their values (Parahoo, 2006 in Palaganas, Sanchez, Molintas, \& Caricativo, 2017), social background, location and assumptions that would affect the research practice (Palaganas, Sanchez, Molintas, \& Caricativo, 2017). Reflexivity also help to identify how the interviews affecting the researchers and the research process by adapting a research method that better suit the context, enhancing the quality of the study, and improving interaction with the research population. Therefore, reflexivity can promote humanity, increase rigor and credibility in qualitative research, and richer data analysis. Moreover, social work researchers and professionals could benefit from reflecting on their practice and understanding the life experiences of the participants to strengthen their research and practice.

\section{References}

Alston, M., \& Bowles, W. (2003). Research for social workers: An introduction to methods (2nd ed.). New York: Routledge.

Ambrosino, R., Ambrosino, A., Heffernan, J., \& Shuttlesworth, G. (2012). Social work and social welfare: An introduction (7th ed.). CA, USA: Brooks/Cole, Cengage Learning.

Barusch, A., Gringeri, C., \& George, M. (2011). Rigor in qualitative social work research: A review of strategies used in published articles. Social Work Research, 35(1), 11-19.

Berger, R. (2015). Now I see it, now I don't: Researcher's position and reflexivity in qualitative research. Qualitative Research, 15(2), 219-234.

Braun, V., \& Clarke, V. (2006). Using thematic analysis in psychology. Qualitative Research in Psychology, 3(2), 77-101.

Buizza, C., Schulze, B., Bertocchi, E., Rossi, G., Ghilardi, A., \& Pioli, R. (2007). The stigma of schizophrenia from patients' and relatives' view: A pilot study in an Italian rehabilitation residential care unit. Clinical Practice and Epidemiology in Mental Health, 3(23), 1-8.

Campbell, A., Taylor, B. J., \& McGlade, A. (2017). Research design in social work: Qualitative and quantitative methods. Thousand Oaks, California: SAGE Publications Inc.

Chong, S. T., Mohamad, M. S., \& Er, A. C. (2013). The mental health development in Malaysia: History, current issue and future development. Asian Social Science, 9(6), 1-8.

Crabtree, S. A. (2004). Strategies of social and sexual control of Malaysian women in psychiatric institutional care. Health Care for Women International, 25(6), 581-595.

Dinos, S., Stevens, S., Serfaty, M., Weich, S., \& King, M. (2004). Stigma: The feelings and experiences of 46 people with mental illness. The British Journal of Psychiatry, 184(2), 176181.

D’Cruz, H., Gillingham, P., \& Melendez, S. (2007). Reflexivity, its meanings and relevance for social work: A critical review of the literature. British Journal of Social Work, 37(1), 73-90.

Etherington, K. (2007). Ethical research in reflexive relationships. Qualitative Inquiry, 13(5), 599-616.

Finlay, L. (1998). Reflexivity: An essential component for all research? British Journal of Occupational Therapy, 61(10), 453-456.

Finlay, L. (2002). "Outing” the researcher: The provenance, process, and practice of reflexivity. Qualitative Health Research, 12(4), 531-545.

Fook, J. (1999). Reflexivity as method. Annual Review of Health Social Science, 9(1), 11-20.

Fossey, E., Harvey, C., McDermott, F., \& Davidson, L. (2002). Understanding and evaluating qualitative research. Australian and New Zealand Journal of Psychiatry, 36(6), 717-732.

Fouka, G., \& Mantzorou, M. (2011). What are the major ethical issues in conducting research? Is there a conflict between the research ethics and the nature of nursing? Health Science Journal, 5(1), $3-14$. 
Galea, S., Nandi, A., Stuber, J., Gold, J., Acierno, R., Best, C. L., Bucuvalas, M., Rudenstine, S., Boscarino, J. A., \& Resnick, H. (2005). Participant reactions to survey research in the general population after terrorist attacks. Journal of Traumatic Stress, 18(5), 461-465.

Gary, F., Sigsby, L. M., \& Campbell, D. (1998). Feminism: A perspective for the $21^{\text {st }}$ century. Issues in Mental Health Nursing, 19(2), 139-152.

Gibbs, L., Molyneaux, R., Whiteley, S., Block, K., Harms, L., Bryant, R. A., ... \& Ireton, G. (2018). Distress and satisfaction with research participation: Impact on retention in longitudinal disaster research. International Journal of Disaster Risk Reduction, 27, 68-74.

Gilburt, H., Rose, D., \& Slade, M. (2008). The importance of relationships in mental health care: A qualitative study of service users' experiences of psychiatric hospital admission in the UK. $B M C$ Health Services Research, 8(92), 1-12.

Gill, P., Stewart, K., Treasure, E., \& Chadwick, B. (2008). Methods of data collection in qualitative research: Interviews and focus groups. British Dental Journal, 204(6), 291-295.

Granerud, A., \& Severinsson, E. (2003). Preserving integrity: Experiences of people with mental health problems living in their own home in a new neighbourhood. Nursing Ethics, 10(6), 602613.

Guillemin, M., \& Gillam, L. (2004). Ethics, reflexivity, and 'ethically important moments' in research. Qualitative Inquiry, 10(2), 261-280.

Hanafiah, A. N., \& Bortel, T. V. (2015). A qualitative exploration of the perspectives of mental health professionals on stigma and discrimination of mental illness in Malaysia. International Journal of Mental Health Systems, 9(10), 1-12.

Haque, A. (2008). Culture-bound syndromes and healing practices in Malaysia. Mental Health, Religion \& Culture, 11(7), 685-696.

Haque, A. (2010). Mental health concepts in Southeast Asia: Diagnostic considerations and treatment implications. Psychology, Health \& Medicine, 15(2), 127-134.

Johnson, S., Bingham, C., Billings J., Pilling, S., Morant, N., Bebbington, P., McNicholas, S., \& Dalton, J. (2004). Women's experiences of admission to a crisis house and to acute hospital wards: A qualitative study. Journal of Mental Health, 13(3), 247-262.

Lietz, C. A., Langer, C. L., \& Furman, R. (2006). Establishing trustworthiness in qualitative research in social work. Qualitative Social Work, 5(4), 441-458.

Lietz, C. A., \& Zayas, L. E. (2010). Evaluating qualitative research for social work practitioners. Advances in Social Work, 11(2), 188-202.

Lincoln, Y. S., \& Guba, E. G. (1985). Naturalistic inquiry. Beverly Hills, CA: Sage. Retrieved on 23 August 2018 from https://ethnographyworkshop.files.wordpress.com/2014/11/lincoln-guba1985-establishing-trustworthiness-naturalistic-inquiry.pdf

Ling, H. K. (2007). Indigenising social work: Research and practice in Sarawak. Selangor, Malaysia: Strategic Information and Research Development Centre.

Longhofer, J., \& Floersch, J. (2012). The coming crisis in social work: Some thoughts on social work and science. Research on Social Work Practice, 22(5), 499-519.

Longo, S. \& Scior, K. (2004). In-patient psychiatric care for individuals with intellectual disabilities: The service users' and carers' perspectives. Journal of Mental Health, 13(2), 211-221.

Low, S. K., \& Lee, W. Y. (2015). Promoting better health care services for mental health patients in Malaysia. International Journal of Social Science and Humanity, 5(12), 1030-1034.

Malaysia Federal Constitution. (2010). Malaysia: The Commissioner of Law Revision.

Malaysian Psychiatric Association. (2006). Common misconceptions about mental illness. Retrieved on 1 February 2018 from https://www.psychiatry-malaysia.org/article.php?aid=67.

Manuel, J. I., Hinterland, K., Conover, S., \& Herman, D. B. (2011). "I hope I can make it out there": Perceptions of women with severe mental illness on the transition from hospital to community. Community Mental Health Journal, 48(3), 302-308.

Mays, N., \& Pope, C. (2000). Qualitative research in health care: Assessing quality in qualitative research. $B M J, 320(7226), 50-52$.

McFadyen, J., \& Rankin, J. (2016). The role of gatekeepers in research: Learning from reflexivity and reflection. GSTF Journal of Nursing and Health Care, 4(1), 82-88.

Mills, J. E. (1999). Western responses to Feng Shui. Middle States Geographer, 32, 71-77.

Morley, C. (2015). Critical reflexivity and social work practice. International Encyclopedia of the Social and Behavioural Sciences (2nd ed.). Elsevier. 
Naaeke, A., Kurylo, A., Grabowski, M., Linton, D., Radlord, M. L. (2011). Insider and outsider perspective in ethnographic research. Proceedings of the New York State Communication Association, 2010(9), 151-160.

Noor, N. M. (1999). Roles and women's well-being: Some preliminary findings from Malaysia. Sex Roles, 41(314), 123-145.

Owen, S., Repper, J., Perkins, R., \& Robinson, J. (1998). An evaluation of services for women with long-term mental health problems. Journal of Psychiatric and Mental Health Nursing, 5(4), 281-290.

Padgett, D. K. (2017). Qualitative methods in social work research (3rd ed.). Los Angeles: SAGE Publications, Inc.

Palaganas, E. C., Sanchez, M. C., Molintas, M. V. P., \& Caricativo, R. D. (2017). Reflexivity in qualitative research: A journey of learning. The Qualitative Report, 22(2), 426-438.

Peters, S. (2010). Qualitative research methods in mental health. Evidence Based Mental Health, $13(2), 35-40$.

Pillow, W. (2003). Confession, catharsis, or cure? Rethinking the uses of reflexivity as methodological power in qualitative research. International Journal of Qualitative Studies in Education, 16(2), $175-196$.

Polkinghorne, D. E. (1995). Narrative configuration in qualitative analysis. International Journal of Qualitative Studies in Education, 8(1), 5-23.

Primeau, L. A. (2003). Reflections on self in qualitative research: Stories of family. American Journal of Occupational Therapy, 57(1), 9-16.

Probst, B. \& Berenson, L. (2014). The double arrow: How qualitative social work researchers use reflexivity. Qualitative Social Work, 13(6), 813-827.

Reid, A.-M., Brown, J. M., Smith, J. M., Cope, A. C., \& Jamieson, S. (2018). Ethical dilemmas and reflexivity in qualitative research. Perspectives on Medical Education, 7(2), 69-75.

Rossman, G. B., \& Rallis, S. F. (2003). Learning in the field: An introduction to qualitative research (2nd ed.). Thousand Oaks, California: Sage Publications, Inc.

Stuckey, H. L. (2013). Methodological issues in social health and diabetes research: Three types of interviews: Qualitative research methods in social health. Journal of Social Health and Diabetes, 1(2), 56-59.

Sword, W. (1999). Accounting for presence of self: Reflections on doing qualitative research. Qualitative Health Research, 9(2), 270-278. 